\section{International Scientific Journal Theoretical \& Applied Science}

p-ISSN: 2308-4944 (print) ｅ-ISSN: 2409-0085 (online)

Year: 2017 Issue: 03 Volume: 47

Published: $23.03 .2017 \quad$ http://T-Science.org
Abdullo Abduhalilov

Senior scientific researcher

Department of Theory and Practice of Democratic

State Construction, Faculty of social sciences National University of Uzbekistan

Tashkent, Uzbekistan

SECTION 24. Sociological research

\title{
MAIN APPROACHES OF INCREASING OF EFFECTIVENESS OF PUBLIC ADMINISTRATION ACTIVITY MOTIVATION
}

Abstract: In the following article, the author analyzed the main motivational theories in commercial structures and public administration. In addition to this the non-monetary mechanisms of motivation in public administration was examined.

Key words: motivation, public administration, public service, efficiency, justice, management, labor, staff, social package, stimulus.

Language: Russian

Citation: Abduhalilov A (2017) MAIN APPROACHES OF INCREASING OF EFFECTIVENESS OF PUBLIC ADMINISTRATION ACTIVITY MOTIVATION. ISJ Theoretical \& Applied Science, 03 (47): 56-58.

Soi: http://s-o-i.org/1.1/TAS-03-47-12 Doi: crossef https://dx.doi.org/10.15863/TAS.2017.03.47.12

\section{ОСНОВНЫЕ ПОДХОДЫ ПОВЫШЕНИЯ ЭФФЕКТИВНОСТИ МОТИВАЦИИ ДЕЯТЕЛЬНОСТИ ГОСУДАРСТВЕННЫХ СЛУЖАЩИХ}

Аннотация: В данной статье автор проанализировал основные теории процессов мотивации как 8 комерческих структурах, так и системе государственного управления. Автором была выявлена специцика немонитарных механизмов мотивации в системе государственного управления.

Ключевые слова: мотивация, государственное управление, государственная служба, эффективность, справедливость, менеджмент, труд, персонал, сочиальный пакет, стимул.

\section{Introduction}

Исследование, проведенное в области управления показывают, что основой функционирования любой организации безусловно являются люди, поскольку именно человек обеспечивает эффективное использование всех видов ресурсов, имеющихся в распоряжении организации и определяет ее экономические показатели. В свою очередь руководство организации может разрабатывать различные планы и стратегии, создать оптимальную систему обработки информации, установить в организации самое современное оборудование, однако все это будет сведено к нулю если члены организации не будут эффективно осуществлять свою деятельность. Готовность человека выполнять свои функции является одним из ключевых аспектов успешности любой организации. Имея определенное положение, желание и настроение, исходя из определенной системы ценностей, следуя определенным правилам и нормам поведения человек каждую конкретную деятельность персонифицирует, следовательно, очеловечивает ее, придавая ей в определенной степени уникальный характер. Однако из этого никак не следует, что этим процессом невозможно управлять. Напротив, если хорошо знать и понимать что движет человеком, что побуждает его к тем или иным действиям, к чему он стремится, можно, в отличии от принуждения, требующего постоянного воздействия и контроля, построить так управление человеческими ресурсами, что люди сами будут выполнять свою работу лучшим образом и наиболее результативно. Путь эффективного управления человеческими ресурсами лежит через внимание к его природе мотивации.

\section{Materials and Methods}

Как любая другая сфера, так и работники бюджетной сферы, в том числе и государственные служащие, имеют свои особенности мотивации, которые следует 
учитывать в процессе проведения кадровой политики. Оптимально выстроенная траектория профессионального развития, должностного роста позволяет государственному служащему найти свое место в структуре управления и стимулирует его полному раскрытию профессионального, делового и личностного потенциала. Исходя из вышесказанного необходимо отметить, что мотивация это моральное и экономическое стимулирование, создание условий для проявлений творческого потенциала работника и его саморазвития. В общем виде процессы мотивации включают в себя установление неудовлетворенных потребностей работника и формулировку целей, направленных на удовлетворение потребностей [1].

Одной из самых известных теорий в области мотивации является теория $\mathrm{X}, \quad \mathrm{Y} \quad$ и $\mathrm{Z}$ Р.Макгрегора. X исходит из того что человек ленив, пытается избегать работы, работники не очень честолюбивы, боятся ответственности и хотят чтобы ими руководили для достижения целей организации, работников нужно принуждать для осуществления ими своих функций. Теория $\mathrm{Y}$ строится на противоположных постулатах: нежелание работать это не врожденное качество человека, а является следствием плохих условий труда, которые подавляют прирожденную любовь к труду. При благоприятных обстоятельствах работники пытаются брать на себя ответственность за работу организации, вознаграждение и личностное поощрение являются важными элементами эффективности организации. Теория же Zявляется серединой двух вышеупомянутых теорий. Вопрос в преобладании удельного веса в организации теории Х или теории Y [2].

Помимо теории X, Y и Z Р.Макгрегора наиболее известной теорией также является теория У.Уолча, в которой особое внимание уделяется коллективной мотивации персонала и раскрепощения инициативности работника. Также сегодня в науке широкую известность получила теория пирамиды потребностей А.Маслоу, отраженная во всех учебниках по управлению. В ней потребности человека разделены на пять основных категорий: основные физиологические потребности (пища, одежда, жилье), потребность в безопасности, уверенность в завтрашнем дне, потребность в социальной общности, принадлежности, причастности человека к той или иной группе, потребности в уважении и самоуважении, признание его и самоутверждение, потребность в самореализации [3].

Также необходимо подчеркнуть такие теории как двухфакторная теория Э.Гедсберга, трудовая мотивация В.Аткинсона, теория справедливости С.Адамса, теория ожидания В.Врума. Заметное место среди них занимает теория справедливости С.Адамса. По его мнению, включаясь в трудовую деятельность, работник оценивает свою ситуацию по двум параметрам: что я даю организации и какое вознаграждение я получаю? Каждый работник сравнивает свои вознаграждения и затраты с другими работниками и врезультате он оценивает ситуацию в контексте: была ли проявлена в отношении к нему справедливость [3]?

Важно отметить, что проблема мотивации труда у государственных служащих сводится к тому, что во многих странах мира заработная плата у государственных чиновников ничтожно мала и жестко определена ставкой. В этой ситуации одним из возможных методов повышения мотивации государственных служащих являются немонетарные методы мотивации. Здесь важную роль в процессе стимулирования труда, по мнению многих исследователей, играют присвоение квалификационных разрядов государственным служащим. Передовой опыт государственной службы предлагает сопровождение карьеры чиновника начиная с приема на работу вплоть до его увольнения. Такой подход позволяет видеть работнику перспективу своей деятельности, что в свою очередь дает ему уверенность в завтрашнем дне [4]. Наиболее стимулирующим фактором является система пожизненного найма, которая наиболее ярко представлена в японском менеджменте [3].

К немонетарным методам мотивации также можно отнести награждение различными грамотами, присвоение каких либо званий, вручение памятных сувениров. Самым простым, привычным для многих способом немонетарной мотивации является составление для сотрудников так называемого компенсационного пакета, который в зависимости от потенциальных возможностей организации включает в себя карточку на бесплатный проезд, бесплатное питание, страховку, возможность регулярного посещения спортивного зала [5].

Также к немонетарным методам мотивации относятся простые слова благодарности, поздравления сотрудников с днем рождения, организация различных образовательных процессов и спортивных соревнований, корпоративных мероприятий с учетом пожеланий персонала, грамотная организация профессиональной адаптации новых сотрудников. Кроме того здесь необходимо упомянуть систему банков отпусков, когда работнику требуется взять для выполнения своих нужд один или несколько дней. В данном случае он может пользоваться запасом из банка отпуска 


\begin{tabular}{|c|c|c|c|c|c|c|}
\hline Impact Factor: & $\begin{array}{l}\text { ISRA (India) } \\
\text { ISI (Dubai, UAF } \\
\text { GIF (Australia) } \\
\text { JIF }\end{array}$ & $\begin{array}{l}=1.344 \\
=0.829 \\
=0.564 \\
=1.500\end{array}$ & $\begin{array}{l}\text { SIS (USA) } \\
\text { PИНЦ (Russia } \\
\text { ESJI (KZ) } \\
\text { SJIF (Morocco }\end{array}$ & $\begin{array}{l}=\mathbf{0 . 9 1 2} \\
=\mathbf{0 . 2 3 4} \\
=\mathbf{1 . 0 4 2} \\
=\mathbf{2 . 0 3 1}\end{array}$ & $\begin{array}{l}\text { ICV (Poland) } \\
\text { PIF (India) } \\
\text { IBI (India) }\end{array}$ & $\begin{array}{l}=6.630 \\
=1.940 \\
=4.260\end{array}$ \\
\hline
\end{tabular}

[5]. Важным стимулирующим фактором выступает философия организации, повышающая патриотизм персонала, его любовь к данному учреждению. Забота о карьере чиновника является важным фактором мотивации его труда. Практика управления коммерческими организациями и системой государственной службы показывает, что мотивация персонала является важным элементом повышения эффективности деятельности любой организации.

\section{Conclusion}

Исходя из концептуальных и прикладных аспектов, которые нами были указаны выше, мы можем прийти к следующим выводам:

1. Сегодня существует необходимость формирования и реализации в Узбекистане концепции повышения мотивации государственных служащих.

2. В процессе повышения мотивации государственных служащих необходимо обратить внимание на исследование уровня мотивированности персонала.

3. Каждое ведомство в стратегии своего развития должно уделять особое внимание механизмам повышения эффективности мотивации труда государственных служащих.

Именно, выше нами описанные механизмы в перспективе, на наш взгляд, будут способствовать повышению эффективности и результативности системы государственного управления в Республике Узбекистан.

\section{References:}

1. Koval' D, Balashev YK (2002) Motivaciya i stimulirovanie personala: osnovy postroeniya sistemy stimulirovaniya. // Marketing v Rossii i za rubezhom. 2002. №7. p. 65.

2. Krasovskiy Y (2006) Upravlenie povedeniem v firme. Prakticheskoe posobie. M. Infra-M. 2006. p. 68 .

3. Bazarov TY (2007) Upravlenie personalom. M. Logos. 2007. p. 319, p. 328, p.55.

4. Ivanov FP (2006) Gosudarstvennaya sluzhba v Rossii i upravlenie personalom. M. 2006. p.66.
5. Zinchenko GP (2000) Sociologiya gosudarstvennoy i municipal'noy sluzhby. // Socis. 2000. № 6. - p. 65, p.60.

6. Norkulov S (2015) Fukarolik zhamiyati va izhitmoiy ongda transformaciya zharayonlariToshkent: Navro'z, 2015.- p.130.

7. Musaev F (2007) Demokratik davlat kurishning falsafiy-xukukiy asoslari- Toshkent Uzbekiston, 2007.- p.272. 